\title{
Crema dental a base de las propiedades medicinales y terapéuticas del aceite esencial del geranio (Pelargonium $x$ hortorum)
}

\author{
Dental cream-based Medical and Therapeutic Properties of Essential Oil \\ of Geranium (Pelargonium x hortorum)
}

\author{
Karolina V. Flores Huamán, Susan Laime Soto*
}

http://dx.doi.org/10.21503/CienciayDesarrollo.2008.v9.09

\section{RESUMEN}

Dada la importancia del geranio (Pelargonim $x$ hortorum) en nuestra región, por ser una planta que crece abundantemente todo el año y su cultivo no necesita mayores cuidados, y presentar propiedades terapéuticas y farmacológicas excepcionales, se realizó su estudio fitoquímico para comprobar y determinar sus principios activos, los mismos que tienen efectos terapéuticos sobre la salud.

El estudio comprende la purificación de los metabolitos secundarios de la planta, dentro de ellos los aceites esenciales, a través de marchas fitoquímicas para evidenciar y detectar los mismos mediante pruebas fisicoquímicas y farmacológicas.

El aceite esencial del geranio, una vez aislado y purificado, se usó en la preparación de una crema dental, extractos y colutorios, los cuales tendrían la propiedad de evitar las caries dental y las enfermedades periodontales, sobre todo en las personas de menores recursos, por ser un producto muy económico.

Se realizaron bioensayos para determinar la actividad de sus principios activos. También se realizaron análisis microbiológicos para evidenciar el efecto antibacteriano del geraniol (aceite esencial del geranio). Se comprobó que el extracto oleoso tiene un poder de inhibición considerable sobre el crecimiento bacteriano, especialmente sobre los gérmenes que causan la placa bacteriana y la caries dental. En el experimento realizado de las diez placas en estudio, nueve inhibieron por completo el crecimiento bacteriano en las zonas tratadas, y solo una no lo hizo.

El control de calidad analítico se realizó partiendo de la muestra, y comprendió todas las etapas de los análisis fisicoquímicos y bacteriológicos.

Palabras clave: metabolitos, aceites esenciales, geraniol.

\section{ABSTRACT}

Given the importance of geranium (Pelargonim $\mathrm{x}$ Hortorum) in our region as a plant that grows abundantly throughout the year and the crop does not need greater care, and pharmacological properties and therapeutic exceptional therefore phytochemical study was conducted to verify and determine active ingredients that have therapeutic effects on health.

The study involves the purification of secondary metabolites of the plant within them the essential oils, through marches and phytochemical evidence for detecting chemical and pharmacological tests.

The essential oil of geranium once isolated and purified was used in the preparation of toothpaste, extracts, mouthwashes which have the property to prevent dental caries and periodontal disease particularly in the poor, as a product very economical.

\footnotetext{
* Estudiantes de la Escuela Académico-Profesional de Estomatología de la Universidad Alas Peruanas.
} 
Bioassays were conducted to determine the activity of its active ingredients. Microbiological analysis was also performed to demonstrate the antibacterial effect of geraniumol (essential oil of geranium). It was found that the extract oil is a considerable power of inhibition on bacterial growth, especially on the germs that cause plaque and tooth decay. In the experiment, the ten plates in nine studies completely inhibited bacterial growth in treated areas and only one did not.

Quality control analysis was performed starting from the sample and in all stages of the physicochemical and bacteriological analysis.

Key words: metabolites, essential oils, geraniumol.

\section{INTRODUCCIÓN}

\section{Planteamiento del problema}

La Escuela Profesional de Estomatología de la Universidad Alas Peruanas, Filial Arequipa, bajo la Dirección de la C. D. María Luz Nieto Muriel viene realizando el trabajo de investigación a cargo de los docentes Iboni Fernández Paz y Fernando Pérez Méndez, con el apoyo de alumnos del área de Química y Bioquímica que buscan difundir las propiedades medicinales que tienen los aceites esenciales de geranio (Pelargonium $x$ hortorum) en el campo estomatológico en la prevención y alivio de enfermedades periodontales, tales como piorrea y gingivitis, efectos infecciosos, antiinflamatorios en piel y boca, etc.

\section{Antecedentes teóricos}

El aceite esencial de geranio tiene una potente acción antiinflamatoria, corta las hemorragias, desinfecta y cicatriza. De ahí sus propiedades benéficas en problemas dermatológicos como golpes, úlceras, hongos, aftas de la boca e inflamación de las encías, enfermedades periodontales, del tracto respiratorio y en la prevención del cáncer de colon. Además, reduce la congestión de las mamas, tiene propiedades diuréticas, alivia el agotamiento y alivia el estrés. Es útil también en la sobreexcitación infantil por su acción normalizante sobre el sistema nervioso. Es muy utilizado en la preparación de cremas faciales. El Journal of Pharmacology and Experimental Therapeutics editó en el año 2002 el trabajo del profesor S. Carnesecchi y colaboradores del Laboratorio de Quimioterapia de Estrasburgo (Francia) titulado: "Geraniol: componente del aceite esencial que inhibe el crecimiento y biosíntesis de poliaminas en células humanas del cáncer del colon”.

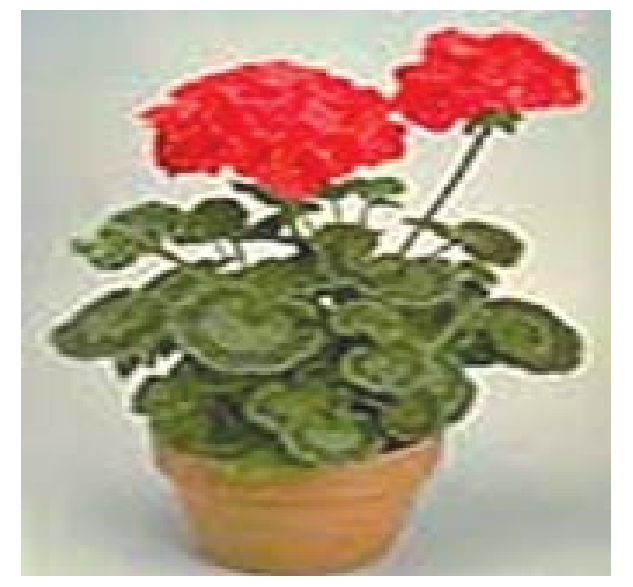

Figura 1. Pelargonium $x$ hortorum

Existen más de 250 especies del género Pelargonium. De lo que llamamos "geranios", los más comunes en nuestro medio son el geranio común (Pelargonium xhrotorum), geranio de olor (Pelargonium graveolens), geranio del pensamiento (Pelargonium grandiflorum), etc. Es una planta que necesita luz solar, pero desarrolla mejor si tiene algo de protección en las horas centrales del día en verano. En climas muy calurosos está mejor en semisombra. Los geranios no resisten las heladas (temperatura 
por debajo de $0{ }^{\circ} \mathrm{C}$ ). Requiere de poca agua, ya que el exceso pudre los tallos. Una carencia de nutrientes provoca un crecimiento lento, apagado, amarillamiento de las hojas y escasez de flores. Crece todo el año en Arequipa. La reproducción es por esquejes. .

La planta del geranio viene siendo usada por la sabiduría popular (etnobotánica) como remedio casero para afecciones pulmonares, hemorragias externas, irritación de encías y otras enfermedades periodontales, como analgésico, antibacteriano, cicatrizante, etc.

En Europa es consumido como alimento altamente apreciado.

Los aceites esenciales o esencias vegetales son productos químicos que forman las esencias odoríferas de un gran número de vegetales. El término aceite esencial se aplica también a las sustancias sintéticas similares preparadas a partir del alquitrán de hulla y a las sustancias semisintéticas preparadas a partir de los aceites naturales esenciales, pero son sustancias químicamente muy complejas, con más de cien componentes. Son líquidosvolátiles, en su mayoría insolubles en agua, pero fácilmente solubles en alcohol, éter y aceites vegetales y minerales. Por lo general no son oleosos al tacto. Pueden agruparse en seis clases, dependiendo de su estructura química: alcoholes, ésteres, aldehídos, cetonas, lactonas y óxidos.

\section{Formulación del problema}

Existe un elevado índice de personas que desconocen las normas básicas de la higiene bucal (niños y adultos) y que no practican la prevención de enfermedades periodontales; desconocen, además, los efectos medicinales y terapéuticos de muchas plantas, dentro de ellas el geranio. Conocer las propiedades antibacterianas de esta planta, que es abundante en nuestra flora regional, nos llevó a realizar esta investigación formulando las siguientes interrogantes: ¿cuál es el efecto del geraniol en la prevención de enfermedades periodontales?, ¿es posible aplicar una crema dental en base a las propiedades medicinales y terapéuticas del aceite esencial de geranio en la higiene bucal y prevención de enfermedades periodontales en niños y adultos de nuestra Región?

\section{Justificación e importancia de la investigación}

Si bien es cierto el geranio es una especie originaria de Sudáfrica, se ha adecuado muy bien al clima en casi todo el Perú, y especialmente en Arequipa, donde existen muchas variedades de este género. Debido a sus propiedades medicinales tiene un amplio uso en el campo de la salud bucal, lo cual motiva su aplicación en la elaboración de productos como la pasta dental, extractos, colutorios, etc.

Al incidir en la sanidad bucal se busca bajar los índices elevados de enfermedades periodontales en personas de todos los estratos.

Se favorecerá la preservación y conservación de nuestra flora en Arequipa, usando nuestros recursos florísticos en el tratamiento de diferentes enfermedades, para lo cual es necesario realizar un estudio e investigación fitoquímica, los mismos que validarán y darán sustento científico al uso medicinal del geranio mediante métodos y técnicas químicas, biológicas, farmacológicas ymicrobiológicas, todas adecuadas y normalizadas.

Pero es necesario demostrar que existen propiedades medicinales y terapéuticas en el aceite esencial del geranio.

El presente proyecto pretende descubrir, comprobar y utilizar propiedades existentes en los aceites esenciales de geranio (geraniol). 


\section{Justificación técnica}

Latecnología para los ensayos de investigación y experimentación estará al alcance de quienes desarrollan el proyecto, no significando esta una limitante.

\section{Justificación económica}

Actualmente, los productos conocidos como naturales son muy preciados en el mercado, por lo que la investigación tendría una retribución económica de lograrse buenos resultados.

Las propiedades fisicoquímicas de los aceites esenciales o esencias son muy diversas, puesto que el grupo engloba substancias muy heterogéneas.

El rendimiento de la esencia obtenida de una planta varía de unas cuantas milésimas por ciento de peso vegetal hasta 1 - 3\%. La composición de una esencia puede cambiar con la época de la recolección, el lugar geográfico o pequeños cambios genéticos.

El aceite esencial de geranio (Pelargonium $x$ hortorum) es un producto natural obtenido de la planta por arrastre de vapor; es uno de los más importantes usados en perfumería yaromaterapia. Es un elemento imprescindible en todo tipo de fragancias, antidepresivo, tónico, astringente, repelente de insectos, además de benéfico para las afecciones pulmonares, hemorragias externas, hemorroides, agotamiento, dolores de cabeza,

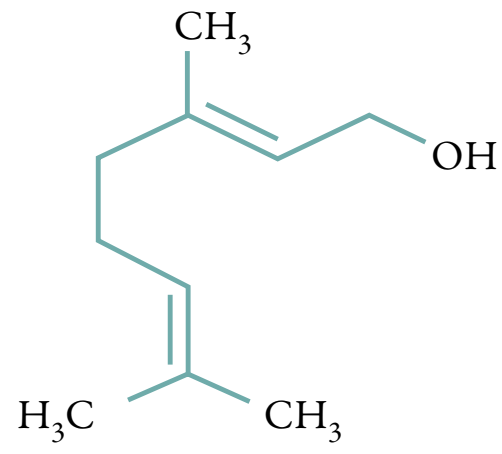

Figura 2. Estructura del geraniol piorrea, etc. Es recomendado en neuralgias faciales, celulitis, estrés y agotamiento. Es un aceite refrescante que equilibra la relación mentecuerpo. Es utilizado en la industria de cosméticos por su excelente papel en el cuidado de la piel, así como en la industria alimentaria en la preparación de jamones, budines, salsas, bebidas, etc.

\section{Fundamento teórico de la investigación}

La investigación de nuestra flora regional y local ayudará a conocer la fisiología y bioquímica de las plantas medicinales y lograr su mejor aprovechamiento con fines científicos y económicos, preservando nuestra salud y la de las personas que no tienen acceso a postas médicas o poseen escasos recursos económicos.

Es necesario conocer la estructura de los aceites esenciales que se encuentran presentes en el geranio, como sonlos terpenos, triterpenos, cesquiterpenos, esteroides, etc., que son compuestos carbonados de 6 unidades de isopreno (componente de muchos vegetales). El isopreno contiene 5 unidades de carbono: $\mathrm{CH}_{2}=\mathrm{C}\left(\mathrm{CH}_{3}\right)_{-}$ $\mathrm{CH}=\mathrm{CH}_{2}$ ) (fórmula global: $\left.\left(\mathrm{C}_{5} \mathrm{H}_{8}\right)_{n}\right)$. Es muy usado en la medicina bionergética.

La placa dentobacteriana que se forma por la mala higiene bucal es la causa principal de enfermedades de las encías, las mismas que pueden ocasionar incluso la pérdida de los dientes, ocasionar infarto al miocardio y provocar nacimientos prematuros en seres humanos.

El estudio comprende el aislamiento, caracterización, separación y valoración por síntesis orgánica de las esencias naturales del geranio, lo cual se realizara en varias etapas o fases.

Lo que se pretende con esta investigación es preparar una crema dental, a base de esencia del geranio, que por sus propiedades antiinflamatorias logre la prevención y el alivio de las enfermedades periodontales. 
LaAcademiadeOdontologíaGeneraldeUSA recomienda que antes de usar cualquier dentífrico se consulte la opinión del odontólogo.

La determinación botánica fue realizada en la Universidad Nacional de San Agustín

Laespeciepertenecealasiguienteclasificación taxonómica.

$\begin{array}{ll}\text { Reino } & : \text { Vegetal } \\ \text { Clase } & : \text { Angiosperma } \\ \text { División } & : \text { Dicotiledónea } \\ \text { Familia } & : \text { Gruinales } \\ \text { Género } & : \text { Geraniáceas } \\ \text { Orden } & : \text { Pelargonio } \\ \text { Especie } & : \text { Pelargonium x hortorum } \\ \text { Nombre } & \end{array}$

\section{Objetivos de la investigación}

\section{Objetivos generales}

- Determinar la posibilidad de aplicar una crema dental en base a las propiedades medicinales y terapéuticas del aceite esencial de geranio en la higiene bucal y prevención de enfermedades periodontales de niños y adultos de nuestra región.

\section{Objetivos especificos:}

- Conocer las propiedades fisicoquímicas, biológicas, medicinales y las estructuras funcionales de los aceites esenciales de algunas variedades de geranio.

- Identificar cualitativamente los metabolitos secundarios mediante pruebas y análisis adecuados, en la extracción del aceite esencial del geranio, dando a conocer sus componentes.

- Preparar una crema dental a base del aceite esencial del geranio (geraniol).
- Realizar estudios de mercado y concientizar a la población en el uso de cremas dentales en base a plantas medicinales típicas de la región.

- De aprobarse el presente proyecto, se convertiría en un proyecto de inversión para el sector industrial, inicialmente en nuestra región, como producto arequipeño, y luego a nivel nacional.

\section{Formulación de la hipótesis}

\section{Hipótesis}

- El geraniol ayuda en la prevención de las enfermedades de la cavidad oral.

- La elaboración de una crema dental en base al aceite esencial de geranio (Pelargonium $x$ hortorum) tiene propiedades medicinales y terapéuticas, y por lo tanto puede utilizarse en la higiene bucal y la prevención de enfermedades periodontales en niños y adultos.

\section{Variables}

\section{Diseño}

Experimental y aplicado.

\section{Tipos de variables}

- Variable independiente: Principio activo del geranio (geraniol).

- Variable dependiente: Prevención de las enfermedades periodontales.

- Indicadores: Principios activos del geranio (geraniol).

\section{Definición conceptual:}

A. De la variable independiente

El principio activo del geranio (geraniol) es un alcohol primario que tiene la propiedad de inhibir la formación de la placa bacteriana. 
B. De la variable dependiente (enfermedades dentales)

Se denomina enfermedad bucal al estado fisiológico anormal de un organismo. El mal olor de la cavidad oral produce la halitosis. La placa bacteriana es una masa de gérmenes heterogéneos y dañinos que se forma en pocas horas y se encuentra en la boca, fijándose a los dientes y causando caries dentales y otras enfermedades en las encías. Las encías sangrantes (gingivitis) producen un aflojamiento de los tejidos que mantiene los dientes, y estos se destruyen y se pierden.

\section{Definición operacional de variables}

A. De la variable independiente

- Propiedades físicas del geraniol. Es un aceite siruposo de color y olor característico a rosas, usado en aromaterapia y perfumería.

- Propiedades químicas. Es un alcohol primario que se puede reconocer con reactivos característicos para este grupo (-OH). Se oxida dando reacciones positivas de aldehídos. Con los ácidos forma ésteres de olores agradables.

- Componentes estructurales del aceite esencial. Sus principales componentes son: geraniol (alcohol primario), terpenos, sesquiterpenos, flovonoides, carotenoides, ácido salicílico y otros.

- La crema dental a base del geranio es un producto óptimo en la prevención de la salud oral, pues inhibe el crecimiento del Estreptococo mutans, que es la bacteria que produce la caries.

B. De la variable dependiente.

Enfermedades de la cavidad oral como:

- Ginvivitis: enfermedad periodontal que produce encías sangrantes y periodontitis, enfermedad irreversible con pérdida de dientes.

- Halitosis: mal aliento provocado por la proliferación de la placa bacteriana, que es producto, a su vez de la mala higiene bucal.

- Úlceras necrotizantes (gunas)

- Tener en cuenta la frecuencia de higiene bucal en pacientes.

- Considerar el tipo de alimentos que consumen.

Sujeto de estudio: Geranio (Pelargonium $x$ hortorum) y pacientes y animales.

\section{Instrumentos:}

- Equipo de extracción de soxhlet y de arrastre con vapor.

- Pacientes (personas, animales en experimentación).

\section{Plan de análisis}

- Los resultados se presentarán en tablas, gráficos, etc.

- Se utilizarán diseños factoriales como método estadístico para la interpretación de resultados.

\section{MATERIAL Y MÉTODO}

Tipo y nivel de investigación: Experimental y aplicada.

\section{Métodos de la investigación:}

- Muestreo. En la recolección de la muestra de geranio se consideraron los siguientes aspectos:

- Clima despejado, no lluvioso.

- Horario: últimas horas de la tarde.

- Estado vegetativo: en floración.

- Período de crecimiento: estado foliar.

- Cantidad: 10 kg. Depositados en bolsas 
de papel y cajas de tecnopor rotuladas.

- Lugar de muestreo: departamento de Arequipa, distritos de Cercado y Sabandía.

- Fecha de muestreo: junio de 2006.

- Suelo: superficial y pedregoso.

Las plantas enteras representativas seleccionadas constituyeron los vouchers para la identificación.

- Preparación de la muestra: se sometió a operaciones de limpieza, selección, secado, estabilización y molienda.

- Determinación de humedad: se realizó por desecación de la muestra en estufa a $110^{\circ} \mathrm{C}$, hasta un peso constante.

- Análisis organoléptico: color, olor, sabor y textura característicos.

Se realizaron pruebas fitoquímicas preliminares en la muestra desecada para caracterizar la presencia o ausencia de metabolitos secundarios. Se realizó la marcha fitoquímica:

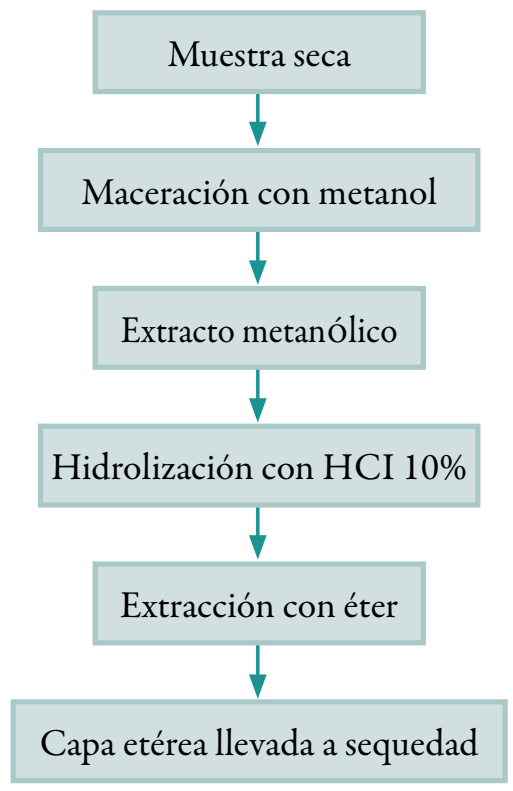

Figura 4. Marcha fitoquímica (1) a) Método de extracción: de Soxhlet.

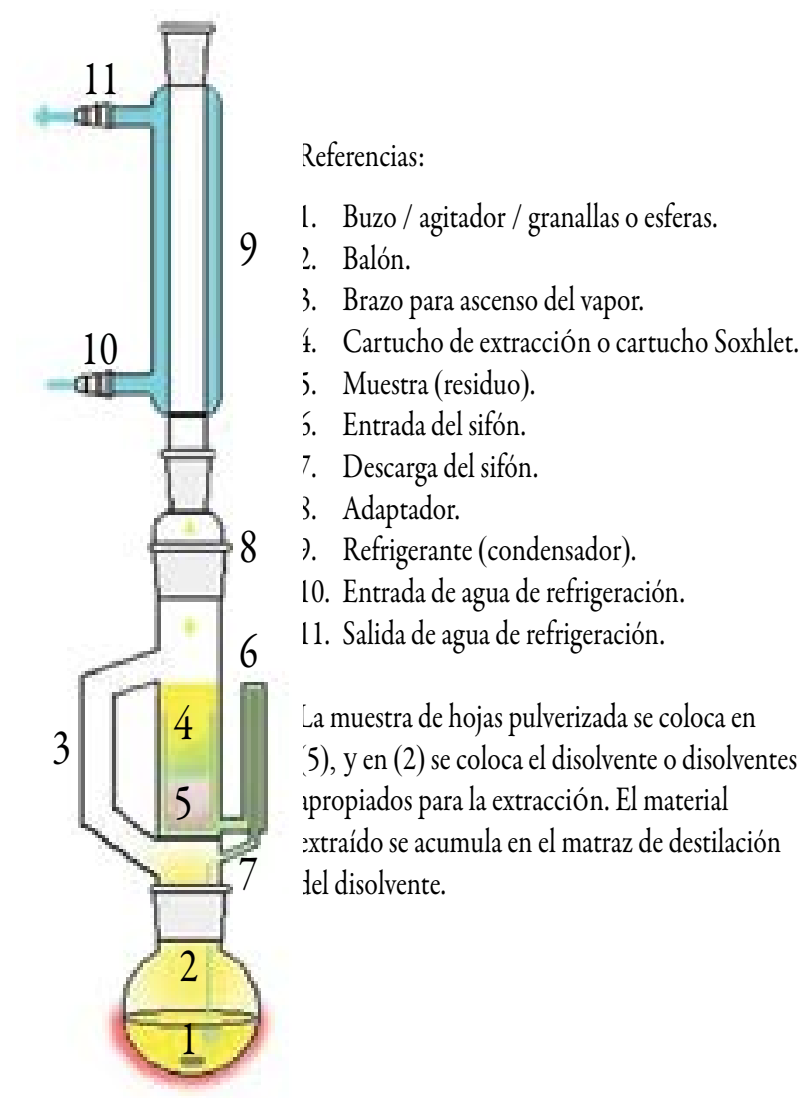

Figura 3. Equipo de extracción de Soxhlet para extracción continua líquido - sólido

10g DE MUESTRA SECA

en $100 \mathrm{~mL}$ de metanol

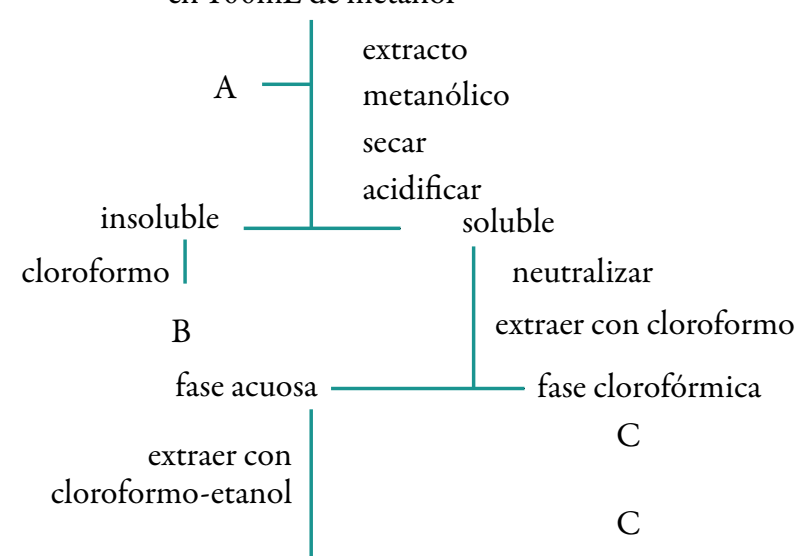

fase clorfórmica-etanólica

$\mathrm{D}$

fase acuosa

$\mathrm{E}$

A : taninos, compuestos fenólicos, flavonoides, aminoácidos.

B : Esteroides-triterpenos, quinonas.

C : Esteroides-triterpenos, alcaloides, cardenólidos.

D : Esteroides-trierpenos, flavonoides, alcaloides, cardenólidos, leucoantocianidinas.

E : Lucoantocianidinas, flavonoides.

Figura 5. Esquema resumen de la marcha fitoquímica (2) 
b) Los aceites esenciales se obtienen por uno de los métodos siguientes:

1. Destilación en corriente de vapor.

2. Extracción con disolventes volátiles.

3. Expresión a mano o a máquina.

4. Enfleurage: proceso en el cual se utiliza grasa como disolvente.

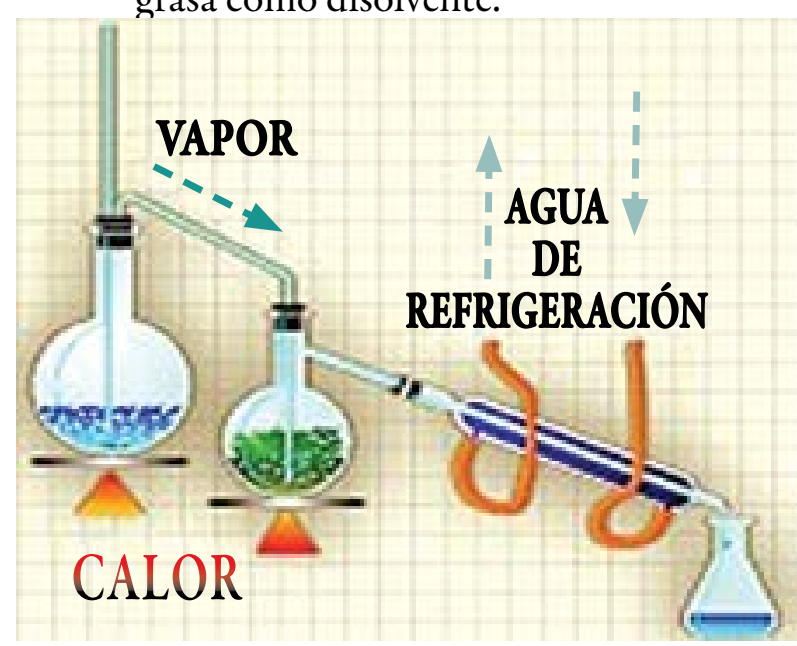

Figura 6. Esquema de equipo de arrastre por vapor

El método utilizado para la extracción del aceite esencial de geranio es el tradicional arrastre por vapor, el cual consiste en hacer evaporar agua en una cámara especial y conducir el vapor hacia la zona donde se encuentran las hojas secas de geranio, de tal manera que el vapor caliente ingrese al interior de las hojas arrastrando el aceite contenido en ellas para luego ser conducido a un sistema de refrigeración y de esta manera retornar al estado líquido, en donde por diferencia de densidades el aceite y el agua se separan. En la figura se ilustra este método. Posteriormente, para una cuantificación y evaluación del porcentaje de rendimiento se procederá a realizar la marcha fitoquímica con el fin de purificar cada vez más el aceite esencial.

c) Propiedades y análisis fisicoquimicos realizados en el aceite esencial (geraniol) obtenido en el laboratorio

NOMBRE TRIVIAL: Geraniol.

NOMBRE IUPAC: 2,6 - dimetil - 2,6 octadien $-8-$ ol.
PESO MOLECULAR: 154,25 u.m.a.

ESTADO FÍSICO: Aceite siruposo.

COLOR: Ámbar, amarillo pálido.

OLOR: Característico a geranio (parecido a rosas).

PUNTO DE FUSIÓN: $15^{\circ} \mathrm{C}$. (determinación efectuada por el método del tubo capilar). PUNTO DE EBULLICIÓN: 229 - $230^{\circ} \mathrm{C}$ (determinación efectuada por el método del tubo capilar o método de Siwolovoff).

GRAVEDAD ESPECÍFICA: 0,870 - 0,885

SOLUBILIDAD EN AGUA: Insoluble $(>0,1 \mathrm{~g} /$ $\mathrm{ml})$.

SOLUBLE: En éter, etílico, cloroformo, alcohol etílico, éter de petróleo, etc.

ÍNDICE DE REFRACCIÓN: 1,469 - 1,478 (realizado con el refractómetro de Abee, para determinar la pureza).

ESTABILIDAD: Estable en condiciones estándar (expuesto a la luz se oxidan. Guardar en recipientes ámbar, en lugar fresco).

Reacción para alcoholes primarios con $\mathrm{HNO}_{3}$ : resultado positivo.

\section{d) Decaracterización}

Pruebas cualitativas, como reacción de coloración y precipitación para verificar la presencia de los diferentes metabolitos en el extracto.

- Pruebas para alcaloides

Reactivo de Dragendorff (nitrato de bismuto en ácido nítrico y yoduro de potasio): al extracto acidulado se agregaron 2 gotas del reactivo. Reacción negativa: no hubo coloración.

Reactivo de Mayer ( $\mathrm{HgCl}_{2}$ y $\mathrm{KI}$ en agua): al extracto acidulado se agregaron 2 gotas del reactivo. Reacción negativa: no hubo coloración.

- Prueba para saponinas

Prueba de la espuma: el extracto se diluyó al doble de su volumen con agua y se agitó por 30 segundos.

Reacción parcialmente positiva. 
- Prueba para flavonoides

Prueba de Shinoda: al extracto etanólico se añadió $\mathrm{HCl}$ concentrado y se agregaron virutas de magnesio metálico.

Reacción positiva.

- Prueba de triterpenos

Reacción Salkowoski: el extracto hexánico se disolvió en cloroformo y se agregó $\mathrm{H}_{2} \mathrm{SO}_{4}$ concentrado.

Reacción positiva.

e) Pruebas fitoquimicas cualitativas de separación y purificación

La más poderosa es la prueba de la cromatografía, de capa fina, HPLC (no se realizó la determinación por falta de equipos).

\section{f) Determinación estructural}

Espectro de masa, infrarrojo, ultravioleta, RMN.H, etc. (no se realizó por la falta de equipos).

\section{Análisis bacteriológico}

Para probar la capacidad antibacteriana del extracto oleoso de geranio obtenido en la investigación, se optó por realizar un cultivo en placas petri de los microorganismos más comunes que se encuentran en la boca, como son los Streptococos mutans.

Para la experiencia se realizaron raspados orales a cuatro donantes anónimos, con la finalidad de obtener una muestra variada de microorganismos.

El cultivo se realizó, según la técnica, sobre la base de agar sangre, y para la comprobación del efecto antibacteriano del extracto oleoso se colocaron pequeños círculos de papel filtro embebidos del extracto, sobre zonas diferentes de la placa.

El crecimiento de las bacterias fue exitoso y a los pocos días las placas estaban completamente pobladas. Los resultados obtenidos se muestran en las imágenes siguientes.

\section{a) Elcultivo}

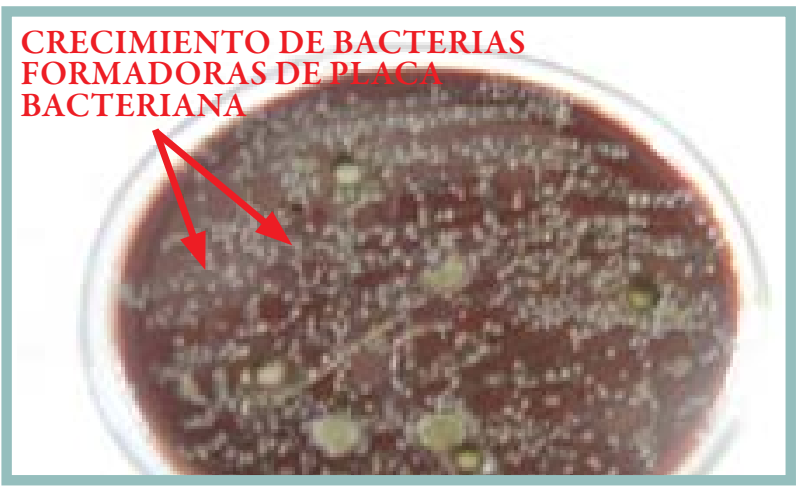

Figura 7. Las bacterias se desarrollan en forma invasiva sobre el sustrato

\section{b) Efecto antibacteriano de los extractos oleosos de geranio}

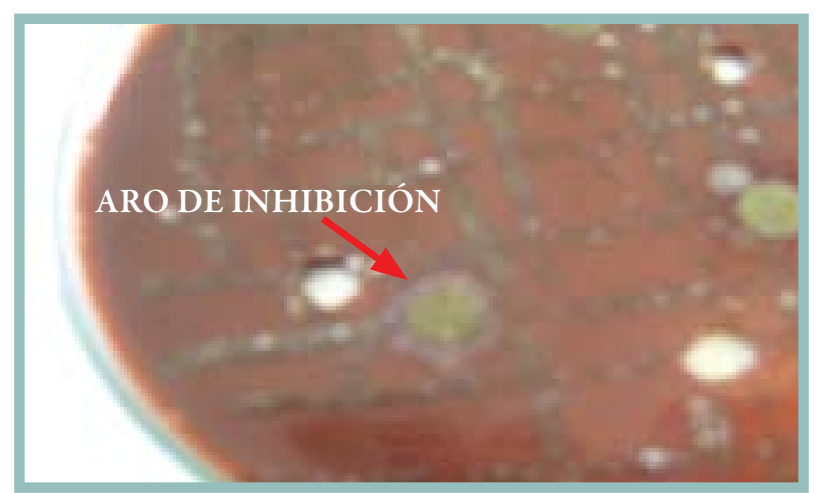

Figura 8. Los círculos verdes son las zonas embebidas con extracto oleoso. En la imagen se muestra claramente que las bacterias se han desarrollado por toda la zona de cultivo, excepto sobre donde se encuentra el círculo rico en el principio activo, formándose un aro de inhibición alrededor

\section{c) Eficacia}

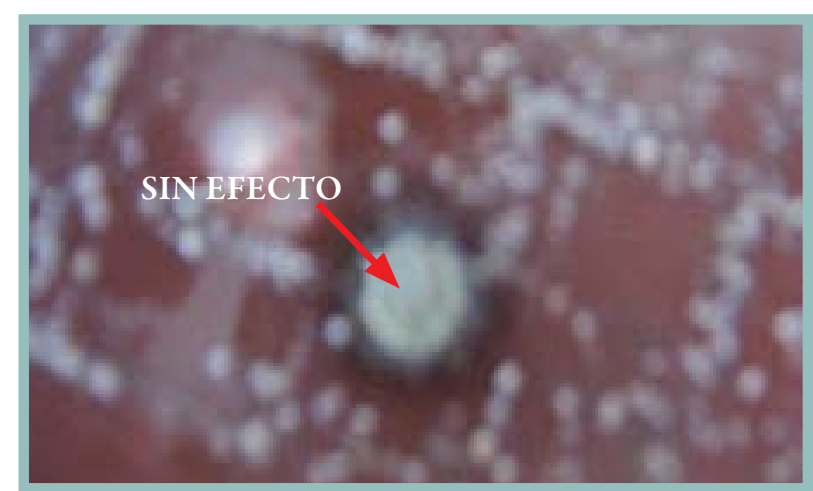

Figura 9. No todas las placas mostraron el mismo resultado de inhibición, caso que se muestra en la imagen, donde las bacterias pudieron desarrollar aun sobre el extracto oleoso. Sin embargo, de las 10 placas solo una manifestó este comportamiento 
En conclusión, se comprobó que el extracto oleoso tiene un poder de inhibición considerable sobre el crecimiento bacteriano, especialmente sobre los gérmenes que causan la placa bacteriana y la caries dental. En el experimento realizado, de las 10 placas en estudio, 9 inhibieron por completo el crecimiento bacteriano en las zonas tratadas, y solo una no lo hizo.

Preparación de la crema dental a base de geraniol

Una vez obtenido el aceite esencial de geranio (Pelargonium xhortorum), se preparó la pasta dental utilizando una fórmula básica.

El producto tiene una fórmula para la fabricación de:

1. Glicerina pura: alcohol que cumple el papel de humectante, muy estable.

2. Conservador (adecuado para cremas dentífricas).

3. Lauril - sulfato sódico en pasta: ésteres del ácido sulfúrico, detergente.

4. Carbonato de calcio precipitado: abrasivo y pulidor, mejora la limpieza.

5. Perborato sódico en polvo: desinfectante.

6. Alcohol etílico de $96^{\circ}$, propio para perfumería: humectante

7. Sacarina en polvo o cristalizada: edulcorante.

8. Esencia de geranio: propiedades bacteriostáticas y desinfectante.

9. Esencia de espliego: saborizante, aglutinante.

10. Timol cristalizado: digestivo.

11. Mentol: analgésico, digestivo.

12. Menta piperita: analgésico en caso de dolores dentales.

13. Agua destilada: disolvente.

El pH debe ser neutro o ligeramente ácido.
Estos productos serán de alta pureza, sin suciedad ni cuerpos extraños, blanquísimos y de una finura de $100 \%$, que pasan por un tamiz de malla de seda número 200, como mínimo. El alcohol puede sustituirse por el de remolacha o de caña refinado.

La mezcla perfectamente limpia se filtra a través de filtro, si fuese necesario, por contener suciedad o cuerpos extraños.

En la siguiente etapa se realizaron pruebas con animales domésticos y posteriormente en seres humanos para comprobar sus efectos benéficos.

El universo lo conforman 60 alumnos del segundosemestre delaEscueladeEstomatología, con historia clínica y cuyas edades fluctúan de 18 a 38 años, además de 30 niños en edad escolar.

Para la muestra se escogieron en forma aleatoria 10 alumnos de la Escuela de Estomatología y 5 niños en edad escolar.

Se realizaron diferentes pruebas de ensayo, dentro de ellas:

- Frecuencia de higiene. Se evaluó el efecto estomatológico del cepillado con crema dental a base de geraniol, con extractos y con colutorios durante tres semanas en alumnos del segundo semestre de la Escuela de Estomatología. El grupo de control A se cepilló con la crema dental 3 veces al día y se observó una reducción significativa de las enfermedades periodontales (si no hay placa bacteriana, no hay enfermedad periodontal).

- Consumo de alimentos. Se observó que el grupo B no tuvo el tratamiento anterior y consumía alimentos cariogénicos, por lo cual aumentó el grado de infección a causa del Estreptococo mutans. 


\section{Contrastación de hipótesis}

\section{Diseño de comprobación de hipótesis}

En base a todos los parámetros considerados en la investigación, la hipótesis se considera válida.

\section{Cronograma de trabajo}

Inicio: enero 2006 Final: diciembre 2007

\begin{tabular}{|c|c|c|c|c|c|c|}
\hline Mes/Actividad & $4-2006$ & $8-2006$ & $12-2006$ & $4-2007$ & $8-2007$ & $12-2007$ \\
\hline Recolección bibliográfica & & & & & & \\
\hline $\begin{array}{l}\text { Revisión del material e } \\
\text { información recopilada }\end{array}$ & & & & & & \\
\hline Pruebas y experimentación & & & & & & \\
\hline $\begin{array}{l}\text { Análisis e interpretación } \\
\text { de resultados }\end{array}$ & & & & & & \\
\hline Informe final & & & & & & \\
\hline
\end{tabular}

\section{Presupuesto:}

\section{ACTIVIDAD}

Recolección de información en bibliotecas, Internet, etc.

Pruebas experimentales durante 2 meses de trabajo (insumos, materiales, equipos, servicios y suministros, etc.)

Otros (imprevistos, daños, pérdidas)

\section{TOTAL}

Nota: En este cuadro no se incluye el costo de la mano de obra especializada, por ser la investigación de interés de los que la realizan.

\section{Presupuesto total aproximadamente: $S / .4500,00$}

\section{Lugares de trabajo}

La parte experimental se realizó en los laboratorios de la UAP, y algunas determinaciones en los laboratorios de la UNSA. Para la determinación estructural del compuesto aislado se pedirá la colaboración de otras universidades.

\section{SUBTOTAL (S/.)}

500,00

$$
2500,00
$$

1500,00

$S / .4500,00$

\section{RESULTADOS}

- Estos estudios y análisis preliminares continúan aún en ejecución, y lo que se pretende es obtener el aceite esencial del geranio en estado puro, para poder preparar una pasta dental con propiedades antisépticas y medicinales.

- Además, con la ayuda de la química instrumental llegar a la elucidación de la estructura del aceite esencial de nuestra localidad. 
- Se vienen realizando estudios comparativos del efecto antibacteriano in vitro de la pasta dental a base del aceite esencial del geranio, la misma que fue posteriormente comparada con un producto comercial.

- Luego de un exhaustivo control de calidad de la pasta dental, se pretende emplearla en la salud bucal de los pacientes de la clínica estomatológica de nuestra universidad.

- Finalmente, luego de realizar el control de calidad de esta pasta dental en seres humanos y el correspondiente estudio farmacológico, se pretende su industrialización ofertándola como un producto de alta calidad $y$ económico.

\section{CONCLUSIONES}

- En el aceite esencial del geranio se identificaron los metabolitos secundarios mediante pruebas cualitativas.

- Se realizaron ensayos biológicos con el aceite esencial y crema dental, obteniéndose resultados positivos reflejados en la eliminación de las enfermedades periodontales.

- El aceite esencial del geranio no muestra la presencia de componentes tóxicos, ni reporta reacciones alérgicas. $\mathrm{Su}$ aroma es agradable y de fácil uso.

- El geraniol puede tener amplios usos en el campo estomatológico, como colutorio, jabón y otros.

- La separación y purificación de los metabolitos secundarios se realizará posteriormente mediante métodos cromatográficos y análisis espectroscópicos para la elucidación de estructuras.

\section{RECOMENDACIONES}

- Verificar los resultados obtenidos en la presente investigación, utilizando técnicas cromatográficas de mayor precisión como la Cromatografía Líquida de Alta Performance (HPLC) y otras.

- Realizar ensayos farmacológicos con los extractos crudos que permitan corroborar o invalidar las propiedades curativas que se le atribuyen al geraniol.

- Buscar que este tipo de estudios se haga extensivo a muchas otras plantas consideradas por la tradición como medicinales.

- Promover el cultivo del geranio en calidad y cantidad.

- Promover la formación de microempresas en nuestro distrito, a fin de que genere fuentes ocupacionales y se eleven las condiciones de vida de la población.

- Las pastas dentales comerciales no cubren los requisitos necesarios para el cuidado apropiado de la higiene bucal, en especial de las encías. Se puede comparar la efectividad clínica de la crema dental medicinal en comparación con la crema convencional, en encías sanas y patológicas.

- Formar equipos de investigación multidisciplinarios.

- Es necesario contar con laboratorios debidamente implementados para realizar investigación fitoquímica, así como conseguir su acreditación.

- El control de calidad analítico se debe aplicar a todos los medios que se emplean. Para realizar análisis químicos, se empezará por la calidad de los reactivos, la calibración de aparatos, la comprobación de métodos analíticos, la reproducción de resultados, el nivel de detección y la sensibilidad de los métodos para establecer su precisión y exactitud. 


\section{REFERENCIAS BIBLIOGRÁFICAS}

- Ames N. Bruce. Detection of carcinogens as mutagens in the salmonella/microsoma test. Acad. SCI (USA), 1986.

- Carnesecchi, S. y col. Journal of Pharmacacology and experimental therapeutics. Strasburg, France, 2002.

- Cotillo, P; Rojas, L. Métodos farmacológicos en investigación de productos vegetales.
Primera edición, Universidad Cayetano Heredia,Perú, 1999.

- Kirschenbauerer, A. Grasas y aceites, Ed. La Educación, 2002.

- Kosel, C. Por la senda de la salud. Ed. Andina

- Aspurth, E. Las cremas al orden del día. Barcelona, España.

- bttp://www.monografias.com 